\title{
Creep of thermoplastic polyurethane reinforced with ozone functionalized carbon nanotubes
}

\author{
Y. Jia ${ }^{1,2}$, Z. M. Jiang ${ }^{2}$, X. L. Gong ${ }^{1}$, Z. Zhang ${ }^{2,3^{*}}$ \\ ${ }^{1}$ CAS Key Laboratory of Mechanical Behavior and Design of Materials, Department of Modern Mechanics, University of \\ Science and Technology of China, 230027 Hefei, China \\ ${ }^{2}$ National Center for Nanoscience and Technology, China, 100190 Beijing, China \\ ${ }^{3}$ Center for Nano and Micro Mechanics, Tsinghua University, 100084 Beijing, China
}

Received 23 February 2012; accepted in revised form 13 April 2012

\begin{abstract}
This work focused on the mechanical behavior, especially creep resistance, of thermoplastic polyurethane (TPU) filled with ozone-treated multi-walled carbon nanotubes (MWCNTs). It was found that the ozone functionalization of MWCNTs could improve their dispersion and interfacial adhesion to the TPU matrix as proved by scanning electron microscope and Raman spectrometer. It finally contributed to the enhancement of Young's modulus and yield strength of TPU/MWCNT composites. Moreover, the creep resistance and recovery of MWCNT/TPU composites revealed a significant improvement by incorporating ozone functionalized MWCNTs. The strong interaction between the modified MWCNTs and TPU matrix would enhance the interfacial bonding and facilitate the load transfer, resulting in low creep strain and unrecovered strain.
\end{abstract}

Keywords: nanocomposites, carbon nanotubes, mechanical properties, creep

\section{Introduction}

Thermoplastic polyurethane (TPU) has been widely used due to its good versatility in material properties. The reinforcement of thermoplastic polyurethane has been investigated in many researches to further improve its performance [1-6]. In general, there are two main approaches: one is changing the molecular structure of polyurethane by modifying its three basic building blocks: polyol, diisocyanate and the chain extender. The other is introducing an inorganic filler into the polyurethane matrix. Carbon nanotubes (CNTs) can be considered as a promising filler which has attracted great attention and generated intense research on their properties as well as their composites with polymers [7]. Interests in this extraordinary carbon form are mainly focusing on exceptional mechanical, electrical and ther- mal properties [8-13]. These properties, in addition to their very high aspect ratio, make nanotubes excellent candidate for novel composite materials. However, there are still several issues in need to be investigated relating to their exceptional properties. Because of their large aspect ratio and high van der Waals interactions, CNTs form easily large agglomerates, which will reduce their positive effect. Meanwhile, the chemical inertness of CNTs is another barrier which will cause poor interfacial interactions between the CNTs and polymer matrix.

Recent research has shown that, modifying the surface properties of CNTs can drastically increase the solubility, processability and dispersibility in solvents and materials. The surface modification of CNTs also has a remarkable effect on polymerCNTs interfacial load transfer and overall bulk rein-

\footnotetext{
${ }^{*}$ Corresponding author, e-mail: zhong.zhang@nanoctr.cn
} (c) BME-PT 
forcement. The wet chemical modification is the most common surface modified method to introduce oxygen-containing moieties onto the CNTs surface. However, these oxidation techniques involve a process which would generate certain organic vapors from the solution-phase oxidation methodologies along with the purification procedures. The vapors are harmful to environment and people's health. Thus, these waste vapors require ultimate disposal. In contrast, the environmentally friendly surface modification of CNTs by ozonation is a relatively new method which is not only powerful and convenient with characteristic of high efficiency, but also has easy operation and potentially low cost [14-17]. Byl et al. [18] utilized ozone as the oxidative agent to modify the nanotube adsorption properties. Electron microscopy studies indicated that CNT bundles were morphologically modified by the ozone agent. Mawhinney et al. [19] studied the gas phase oxidation of CNTs by ozone at room temperature and characterized the change of surface functional groups using Fourier transform infrared spectroscopic (FTIR) method. Simmons et al. [20] exposed CNTs to room temperature UV-generated ozone and found it could lead to an irreversible increase in their electrical resistance, which was due to the oxygen-containing functional groups successfully introduced on the sidewalls of the nanotubes. According to our previous study [21], the ozone-treated MWCNTs were prepared at room temperature and epoxy [22] or polycarbonate [23] based composites filled with ozone treated MWCNTs were studied in terms of mechanical properties. In this work, we prepared thermoplastic polyurethane based composites filled with pristine or ozone treated MWCNTs by melt mixing and compared the mechanical properties as well as creep and recovery behavior.

\section{Experimental methodology}

\subsection{Materials}

The pristine MWCNTs (denoted as p-MWCNTs in this paper) were prepared by a chemical vapor deposition method. Their purity is higher than $95 \mathrm{wt} \%$, average diameter is between 10 and $20 \mathrm{~nm}$, and length is between 1 and $10 \mu \mathrm{m}$. The MWCNTs were supplied by Bayer MaterialScience AG (Leverkusen, Germany). The TPU's brand name is Elastollan 1185A10 (BASF Corporation, Germany) and its density is $1.12 \mathrm{~g} / \mathrm{cm}^{3}$. Before further functionalization or melt-mixing process, the MWCNTs and TPU were dried at $373 \mathrm{~K}$ for 12 hours in a vacuum oven.

\subsection{Functionalization of MWCNTs}

The MWCNTs were functionalized with ozone at room temperature $\left(25^{\circ} \mathrm{C}\right)$, which has been discussed in our recent work [21]. Generally, 3 grams of p-MWCNTs were placed into our in-house vertical reactor each time. During the oxidation process, the ozone continuously passed through the reactor chamber and reacted with the MWCNTs for 2 hours. The functionalized MWCNTs are denoted as f-MWCNTs in this paper.

\subsection{Preparation of nanocomposites}

TPU/MWCNT composites were prepared by a twostep melt-mixing strategy to improve the dispersion of fillers. A twin screw extruder (HAAKE-Polylab OS, Haake being part of Thermo Scientific) is employed during the mixing. A masterbatch included $15 \mathrm{wt} \%$ of MWCNTs in TPU was prepared firstly. Then the TPU/MWCNT masterbatch was diluted to obtain the target proportion of $3 \mathrm{wt} \%$. The screw speed was set to $80 \mathrm{rpm}$. Several heating temperatures of all barrels of the extruder were applied, and the one gave the best mechanical properties of materials was chosen. After extrusion, the TPU/MWCNT composites were cooled down in a water bath and then were finally granulated with a pelletizer. The pure TPU was extruded under the same conditions for quantitative comparisons with the composites.

\subsection{Morphological characterization}

The dispersion state of MWCNTs in the TPU nanocomposites was studied under a scanning electron microscope (SEM, HITAHI S-4800, Japan). The cryo-fractured surfaces of the tensile loaded specimens were subjected to SEM inspection after gold coated at $6 \mathrm{kV}$ acceleration voltage.

\subsection{Raman spectroscopy}

In order to observe the interface between the TPU matrix and nanotubes, the Raman spectra were obtained by a Renishaw 2000 MicroRaman spectrometer (Reinshaw, Wotton-under-Edge, UK) with an excitation length of $633 \mathrm{~nm}$. The TPU/MWCNT samples were put into an obturator in which the 
testing temperature can be continuously cooled down from 60 to $-60^{\circ} \mathrm{C}$ by liquid nitrogen, for the sake of checking the change of compressive stress generated in MWCNTs caused by different temperature-dependent expansion coefficients of nanotubes and TPU matrix. Thermal equilibrium was ensured in all the cases by maintaining the specimen under constant corresponding temperature for $10 \mathrm{~min}$. At least five positions were scanned at each temperature for each sample.

\subsection{Mechanical measurements}

Tensile tests were carried out according to the standard methodology of ASTM D638. The injection molded dog-bone-shaped tensile specimens were applied. The tests were performed using a SANS CMT2000 Tester at a crosshead speed of $50 \mathrm{~mm} / \mathrm{min}$ at ambient temperature. The Young's modulus, tensile strength and elongation at break were measured and ensemble-averaged values are obtained with at least five specimens of each composition.

\subsection{Creep and creep-recovery measurements}

Creep and creep-recovery tests were conducted in tensile mode under different temperatures and stresses using dynamic mechanical analysis (DMA, Q800, TA Instruments, USA). The creep and recoverable strains were determined as a function of the time. Effects of stress level, recovery period and temperature were investigated as run-time parameters, while creep time is set to constant $300 \mathrm{~s}$. The applied creep stress was $2 \mathrm{MPa}$ and $5 \mathrm{MPa}$. The recovery time was 300 and $600 \mathrm{~s}$. Three creep-recovery profiles were obtained at temperatures of 35,80 and $110^{\circ} \mathrm{C}$. The specimen size was $13 \mathrm{~mm} \times 4.3 \mathrm{~mm} \times$ $0.4 \mathrm{~mm}$ (width $\times$ length $\times$ thickness). For each experiment, a new sample was used.

The typical creep-recovery curve of creep tests performed in a tensile configuration was illustrated in Figure 1 [24]. Creep strain $\varepsilon(t)$ in the viscoelastic range can be described by Equation (1):

$\varepsilon(t)=\varepsilon_{\mathrm{E}}+\varepsilon_{\mathrm{V}}+\varepsilon_{\infty}$

where $\varepsilon_{\mathrm{E}}$ is the elastic creep strain, $\varepsilon_{\mathrm{V}}$ is the viscoelastic portion of the strain and $\varepsilon_{\infty}$ is the permanent creep strain. The shear stress $\tau_{0}$ is set to zero at $t_{0}$ and the unrecovered strain $\varepsilon_{\mathrm{r}}\left(t_{0}, t\right)$ is measured in this study. In order to further analyze the influence of the stress cycles and carbon nanotubes on the

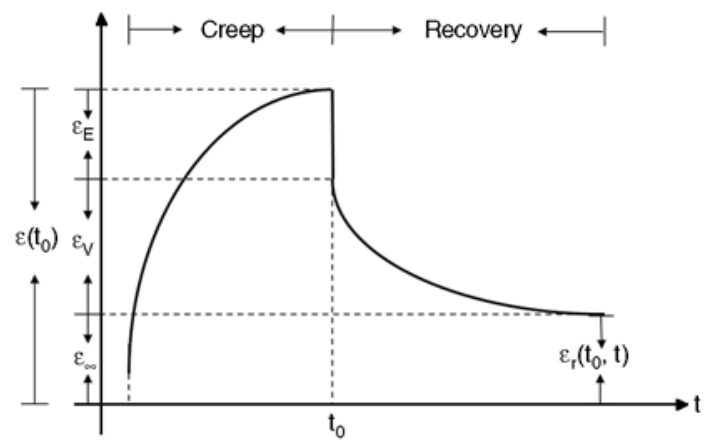

Figure 1. Schematic diagram of a creep-recovery test

recovery performance, the recovery ratio $X_{\mathrm{R}}$ of a system at time $t$ is defined as shown in Equation (2):

$X_{\mathrm{R}}=\frac{\varepsilon(t)-\varepsilon\left(t_{0}, t\right)}{\varepsilon\left(t_{0}\right)} \cdot 100 \%$

\section{Results and discussion}

\subsection{Morphology characterization}

The homogeneous dispersion of nanotubes in polymer matrices is necessary for making high performance composites. The dispersion state of the materials used in this study is investigated by SEM. Figure 2a is the SEM image of the cryo-fractured surfaces of neat TPU. Figure $2 b$ and $2 c$ are the images of composites containing p-MWCNTs and f-MWCNTs respectively with the content of $3 \mathrm{wt} \%$. In order to characterize the state of distribution, a low magnification was selected to observe the fracture surface, which was perpendicular to the injection direction, of TPU/MWCNTs composites. Comparing with the images of pure matrix, one can clearly observe the presence of carbon nanotubes. Generally speaking, the dispersion is pretty good due to careful mixing. As shown in Figure 2b, however, a few agglomerates labeled by white arrow can be observed, which indicates the dispersion state of TPU/p-MWCNT composite is not perfect. After ozone treatment, there exist some polar groups such $-\mathrm{OH},-\mathrm{COOH}$ on the surface of MWCNTs, which can improve the dispersion level of MWCNTs as comparing Figure $2 \mathrm{c}$ with $2 \mathrm{~b}$.

\subsection{Interface quality between MWCNTs and matrix}

Raman spectroscopy can represent the interface quality between CNTs and polymer matrix when the composites are subjected to stress [25-26]. The interaction between CNTs and matrix can be esti- 


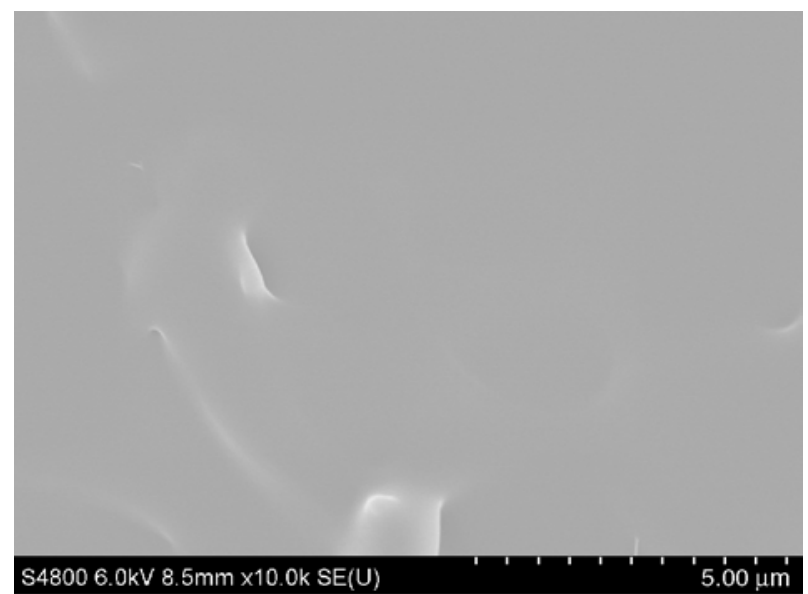

a)

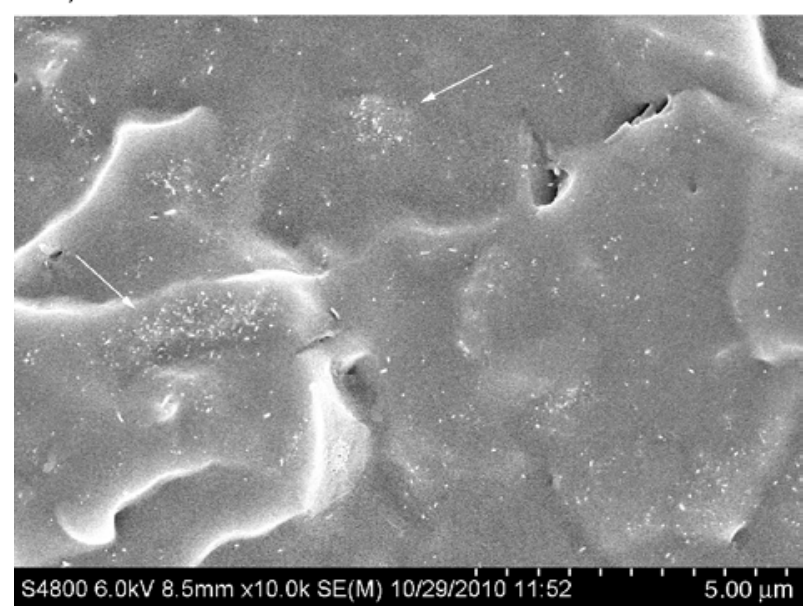

b)

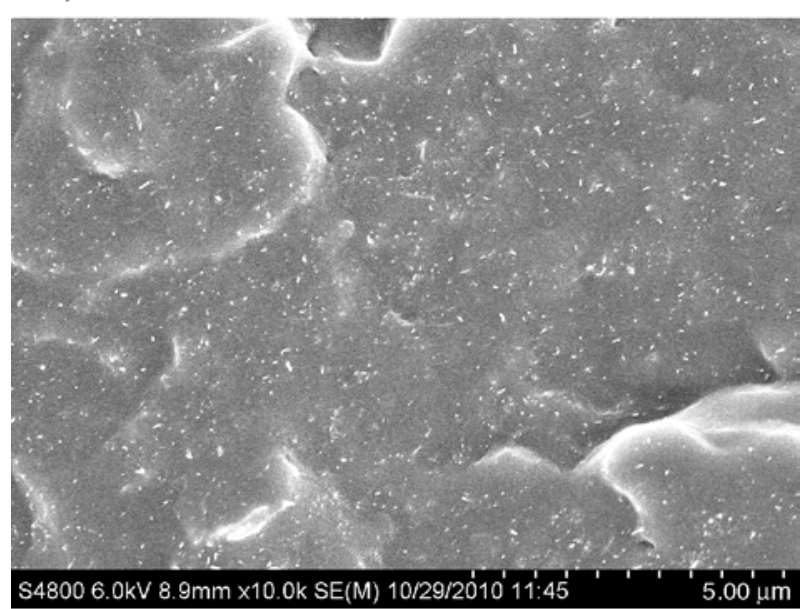

c)

Figure 2. SEM micrographs TPU and TPU/MWCNT nanocomposites: (a) TPU (b) TPU/3.0 wt \% p-MWCNT and (c) TPU/3.0 wt $\%$ f-MWCNT

mated by the Raman shifts of the characteristic peaks. As well established by former research, the $G^{\prime}$-band was found to be exact and convenient for monitoring the temperature-induced strain of CNTs embedded in the polymer matrix. The spectrum shifts to lower wavenumber when nanotubes are subjected to tension and to higher wavenumber in compressied state. In the present study, we induced a compressive deformation of MWCNTs embedded in the TPU matrix by cooling the specimens from 60 to $-60^{\circ} \mathrm{C}$ as showed in Figure 3a. Obvious upward shifts of Raman $G^{\prime}$-band peak for the embedded MWCNTs could be seen as the result of compressive stresses from the matrix. Arising from the further shortening of $\mathrm{C}=\mathrm{C}$ bond also appeared, which is due to the mismatch of thermal expansion coefficients of the MWCNTs and the TPU matrix.

Furthermore, it can be observed that the upward shift of TPU/f-MWCNT composite is more obvious than that of the TPU/p-MWCNT composite (Figure 3a). As shown in Figure 3b, the cooling of the embedded materials from $60^{\circ} \mathrm{C}$ down to $-60^{\circ} \mathrm{C}$ caused 7 and $10 \mathrm{~cm}^{-1}$ shift for p-MWCNTs and f-MWCNTs, respectively. Compared with p-MWCNT filled composite, the f-MWCNTs embedded in TPU matrix shows larger $G^{\prime}$-band shift over the temperature range, indicating more efficient load transfer between the f-MWCNTs and the TPU matrix. Thus, we can come to the conclusion that ozone modification can improve the stress transfer from the matrix to the MWCNTs. In other words, the f-MWCNTs have stronger interfacial bonding with TPU matrix in comparison with the p-MWCNTs.

\subsection{Mechanical properties}

As the fundamental properties of material are of primary importance, the tensile properties of the materials at room temperature have been determined. In order to obtain the best mechanical properties of materials, several heating temperatures of the barrels of the extruder were applied. As shown in Figure 4, the temperatures of 200, 205, 210, 215 and $220^{\circ} \mathrm{C}$ were investigated. The elongation of samples when they are break down raised firstly $\left(200-210^{\circ} \mathrm{C}\right)$ and then descended $\left(210-220^{\circ} \mathrm{C}\right)$ with the increasing temperature. The tensile strength of TPU matrix was very low at $200^{\circ} \mathrm{C}$ and remained constant from 205 to $220^{\circ} \mathrm{C}$ at about $33 \mathrm{MPa}$. Therefore we chose $210^{\circ} \mathrm{C}$ as the processing temperature which can ensure the best mechanical properties of the materials.

Table 1 shows the key mechanical properties of TPU and TPU/MWCNTs nanocomposites. The Young's modulus, tensile strength and elongation at break down for the neat TPU are about $18.1 \mathrm{GPa}, 32.0 \mathrm{MPa}$ 

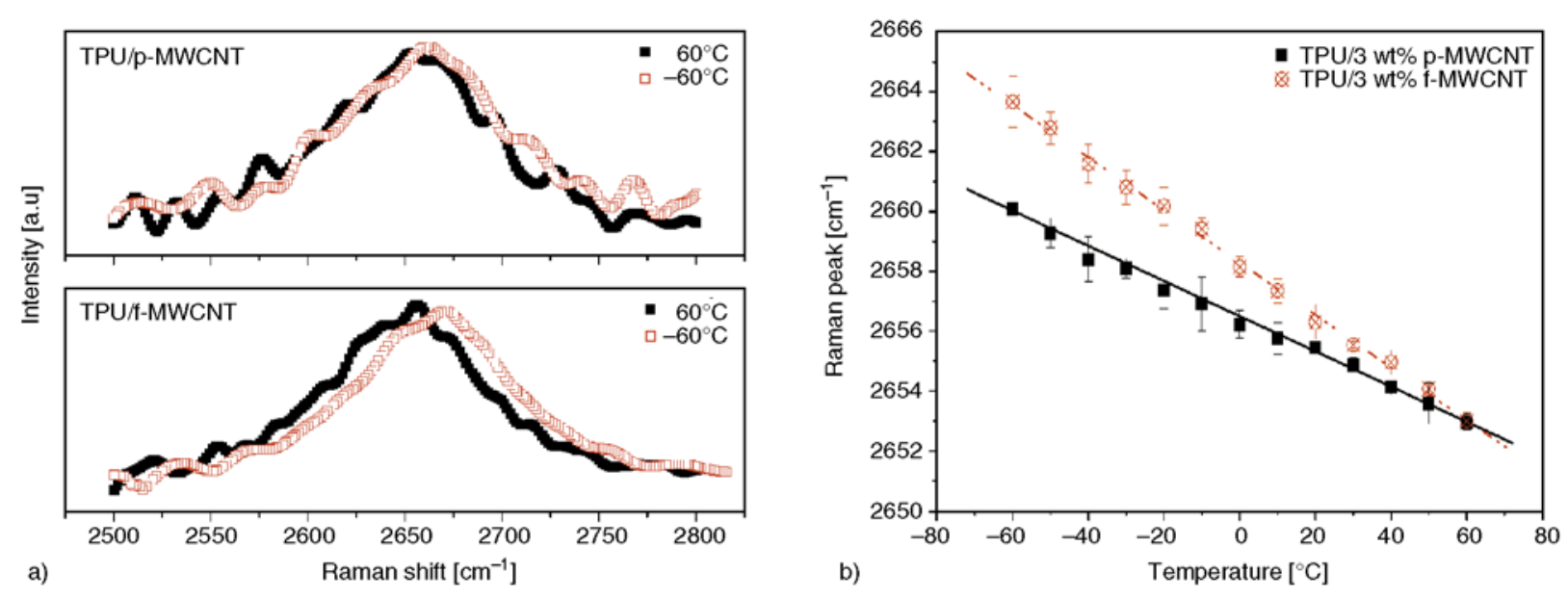

Figure 3. Typical $G^{\prime}$-band Raman spectra. a) Comparison of the Raman spectra for TPU/p-MWCNT and TPU/f-MWCNT composites with the MWCNT content of $3 \mathrm{wt} \%$; b) the Raman shift of $G^{\prime}$-band with the testing temperature changed from -60 to $60^{\circ} \mathrm{C}$.

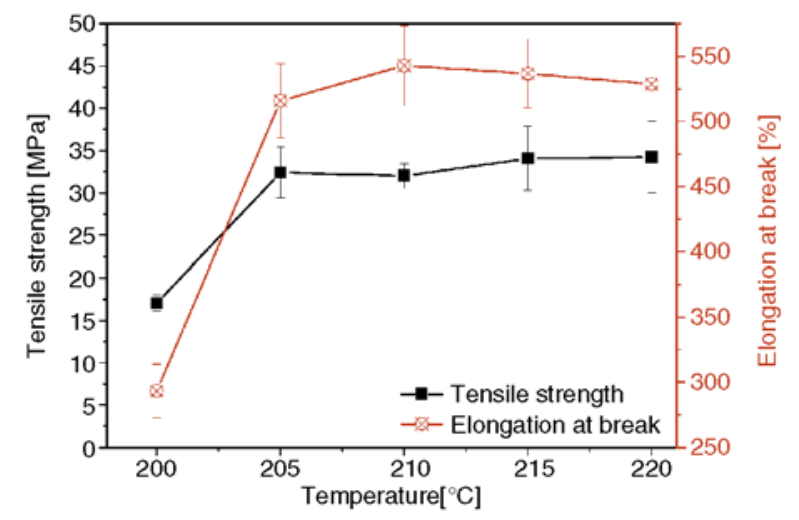

Figure 4. Mechanical properties of TPU with different process temperatures of barrels in a twin screw extruder

Table 1. Tensile mechanical characteristics of the TPU and TPU/MWCNT nanocomposites

\begin{tabular}{|l|c|c|c|}
\hline \multicolumn{1}{|c|}{ Sample } & $\begin{array}{c}\text { Young's } \\
\text { Modulus } \\
{[\mathbf{G P a}]}\end{array}$ & $\begin{array}{c}\text { Tensile } \\
\text { strength } \\
{[\mathbf{M P a}]}\end{array}$ & $\begin{array}{c}\text { Elongation } \\
\text { at break } \\
{[\%]}\end{array}$ \\
\hline TPU & $18.1 \pm 3.9$ & $32.0 \pm 1.4$ & $542.8 \pm 30.6$ \\
\hline $\mathrm{TPU} / 3 \mathrm{wt} \% \mathrm{p}-\mathrm{MWCNT}$ & $21.0 \pm 3.7$ & $35.1 \pm 1.4$ & $621.8 \pm 16.5$ \\
\hline $\mathrm{TPU} / 3 \mathrm{wt} \% \mathrm{f}-\mathrm{MWCNT}$ & $22.4 \pm 0.8$ & $35.5 \pm 0.6$ & $622.1 \pm 12.2$ \\
\hline
\end{tabular}

and $542.8 \%$, respectively. The Young's modulus of the samples rises with increasing MWCNT contents. Addition of $3 \mathrm{wt} \%$ p-MWCNTs causes $16 \%$ increase in the modulus while the addition of $3 \mathrm{wt} \%$ f-MWCNTs increases the value of Young's modulus by $24 \%$. Similar tendency is also observed in the tensile strength as presented in Table 1 . The reinforcement efficiency of carbon nanotubes depends on the effect of the intrinsic mechanical properties as well as on the uniform distribution of MWCNTs and matrix-nanofiller interfacial adhesion [27]. The enhancement effect can be recognized in the nanocomposite systems after addition of either p-MWCNTs or f-MWCNTs in terms of the elongation at break. Even though some minor factors such as nanotube type, aspect ratio, weight fraction, dispersion state and testing conditions may affect the properties as well, the significant improvement found in this study strongly supports that ozone functionalization is an effective method to modify the surface of CNTs and to improve the related mechanical properties of TPU matrix.

\subsection{Creep and recovery behavior}

The creep and recovery behavior is studied in different aspects. First, Figure 5 shows the evolution of the creep and recovered strains as a function of time for the neat TPU under three temperature conditions of 35,80 and $110^{\circ} \mathrm{C}$. In this test, $2 \mathrm{MPa}$ was selected as the applied stress within the elastic range. As it is expected, creep strain increased with temperature. While the temperature increased from 35 to $80^{\circ} \mathrm{C}$, it is apparent that the creep strain increased from 0.12 to 0.18 (by $45 \%$ approximately) at $t=30 \mathrm{~min}$. In our recent work [28], we reported the temperature dependence of creep behavior of polypropylene (PP). It was found that the creep strain of PP could increase by almost $900 \%$ with the increasing temperature from 50 to $80^{\circ} \mathrm{C}$ at $t=$ 30 min. Comparing experimental result of PP with that of TPU, indicates that the creep property is closely related with intrinsic viscoelastic properties of the materials. In the temperature range from 35 to $80^{\circ} \mathrm{C}$, TPU is in the rubber state at all times, 


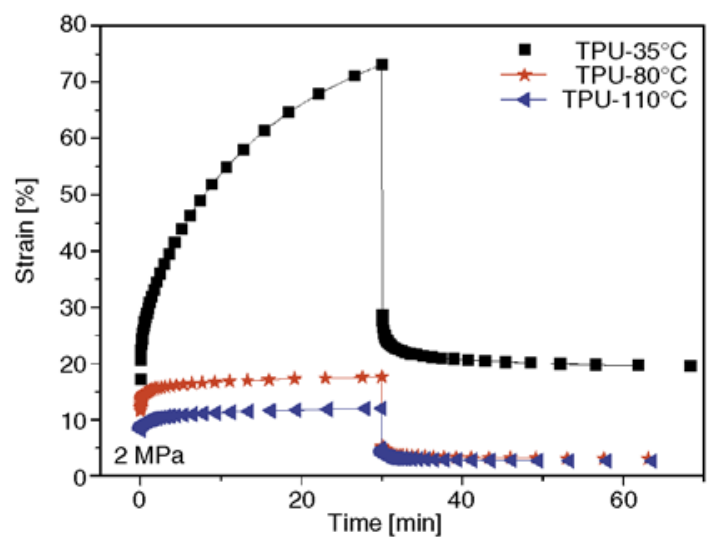

Figure 5. Creep-recovery curves of TPU as a function of time at $2 \mathrm{MPa}$ under three different temperature conditions

while PP starts to enter into the glass-rubber transition state around $80^{\circ} \mathrm{C}$. Thus, the creep strain of PP changes remarkably in this particular temperature range, whereas TPU responds moderately. When the testing temperature rises to $110^{\circ} \mathrm{C}$, the creep strain of TPU exhibits a large increase as shown in Figure 5. It is considered to relate with the softening process of TPU.

Secondly, it is found that temperature has an effect on the elastic property and viscous characteristic of TPU. The evolution of recovered strain as a function of time is also presented in Figure 5. While the elastic creep strain $\varepsilon_{\mathrm{E}}$ recovers immediately, a small deformation of the viscoelastic and viscous response are observed at 35 and $80^{\circ} \mathrm{C}$. The unrecovered strains of TPU are 0.027 and $0.031(t=3600 \mathrm{~s})$ at 35 and $80^{\circ} \mathrm{C}$ respectively, which indicates that the change of recovery property is not sensitive within the testing temperature range of 35 to $80^{\circ} \mathrm{C}$. However, a large unrecovered strain could be observed at $110^{\circ} \mathrm{C}$, illustrating that the viscous characteristic of TPU would gradually appear under high temperature condition.

Besides different temperatures, various loads were also employed to investigate the creep and recovery behaviors of TPU. The resulting TPU creep profiles under stresses of 2 and $5 \mathrm{MPa}$ at the temperature of $35^{\circ} \mathrm{C}$ are presented in Figures 6 and 7. It can be seen that the materials showed different responses to varying stress levels. Comparing Figures 6 and 7, one can recognize that the creep strain and unrecovered creep strain increased distinctly with the increasing stress. The averaged creep strain of pure TPU increased from 0.12 to 1.35 when stress increased

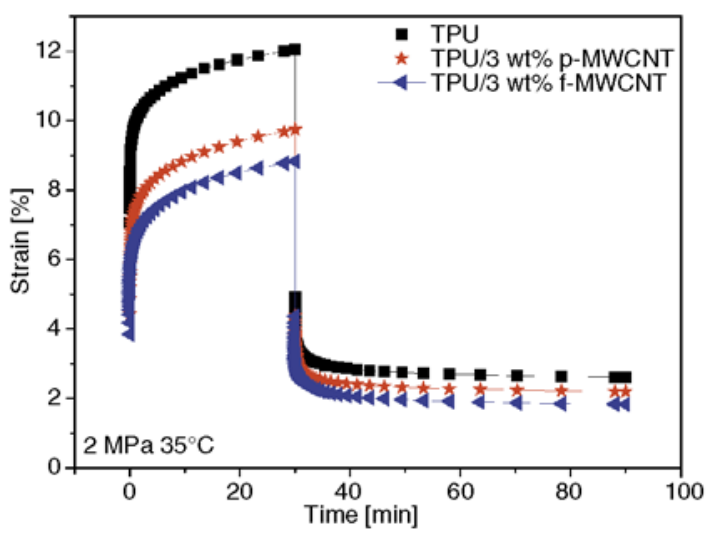

Figure 6. Creep-recovery curves of TPU, TPU/p-MWCNT and TPU/f-MWCNT composites at $5 \mathrm{MPa}$ in the temperature condition of $35^{\circ} \mathrm{C}$

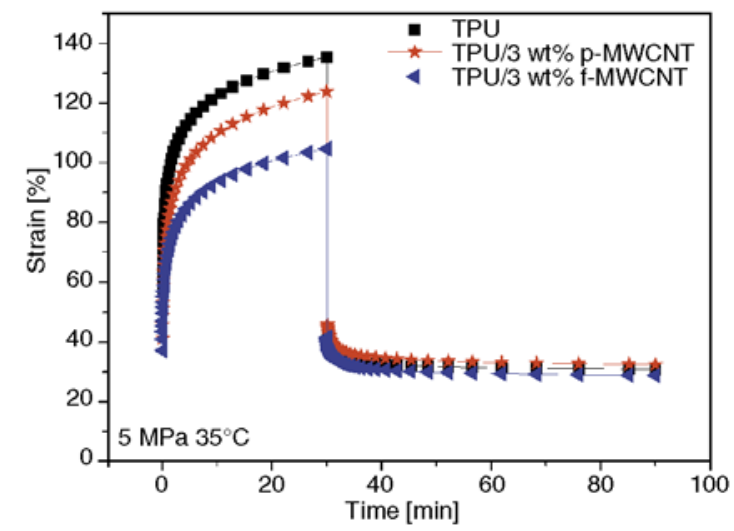

Figure 7. Creep-recovery curves of TPU, TPU/p-MWCNT and TPU/f-MWCNT composites at $5 \mathrm{MPa}$ in the temperature condition of $35^{\circ} \mathrm{C}$

from 2 to $5 \mathrm{MPa}$. The ratio of increasing is about $1: 11$. Similar tendency is also observed for the unrecovered strain $\varepsilon_{\mathrm{r}}$, as presented in Figures 6 and 7. The unrecovered strain $\varepsilon_{\mathrm{r}}$ of TPU increased from 0.03 to 0.31 when stress increased from 2 to $5 \mathrm{MPa}$. Moreover, the recovery ratio $X_{\mathrm{R}}$ is also calculated to analyze the recovery property of the materials. However, there are no substantial changes in the recovery ratio of TPU at 2 and $5 \mathrm{MPa}$ (from $21.7 \%$ to $21.3 \%$ ) at $t=90 \mathrm{~min}$.

After characterizing the features of the pure TPU, our attention turned to the effect of the nanotube fillers. The content of nanocomposites is more important than the internal or basic features of the material. The results shown in Figures 6 and 7 also indicated that creep strains of nanocomposites at filler content of $3 \mathrm{wt} \%$ were lower than those of the neat matrix under both two test stresses. This implies that the creep behavior is improved by the presence of nanotubes. Under the stress of $5 \mathrm{MPa}$, for instance, 
the strain values of TPU/p-MWCNT and TPU/fMWCNT composites were reduced by 8.6 and $22.7 \%$ compared with it of the neat TPU. It proves that by adding either p-MWCNTs or f-MWCNTs to the TPU matrix, the creep resistance could be improved. The difference between the two nanocomposites, meanwhile, indicates that the properties of PS/f-MWCNT composites are better than PS/pMWCNT ones under different loading conditions. The recovery properties of composites could also be obtained to investigate the enhancement effect of the two different types of nanotubes. As shown in Figure 7 under high stress condition, there are no substantial changes in the unrecovered strain after addition of either p-MWCNTs or f-MWCNTs, comparing with the pure TPU. On the other hand, the recovery properties shown in Figure 6 under low stress level can be improved by adding nanotubes as unrecovered strain of nanocomposites reduced. The unrecovered strain values of TPU/p-MWCNT and TPU/f-MWCNT composites at $2 \mathrm{MPa}$ were reduced by 16 and $30 \%$ compared with neat matrix, respectively. Thus the TPU/f-MWCNT composites have better recovery properties at filler content of $3 \mathrm{wt} \%$ than unozonized TPU/p-MWCNT. As the analysis about stress effect mentioned above, it is worth noting that there are different responses of the recovery property of composites under different stress conditions, which is mainly due to the network-like structure formed by the MWCNTs and entangled molecular chain segments. In the two TPU/MWCNTs composites, the network-like structure mixing with nanotubes have good elasticity and recovery feature especially under smaller stress. Moreover, due to the strong interaction between f-MWCNTs and TPU molecular chains, the ozone functionalized nanotubes could further reinforced the composite because the external stresses applied to the composite as a whole can be efficiently transferred to the MWCNTs, allowing the minor content of filler to take a large share of the load in the network-like structure.

For sake of exploring the temperature effect for nanocomposites, the creep and recovery properties of TPU/p-MWCNT and TPU/f-MWCNT composites at $2 \mathrm{MPa}$ in the temperature condition of $110^{\circ} \mathrm{C}$ were investigated. Compared Figure 8 to Figure 6 , it can been seen that the creep strains and unrecovered strains of nanocomposite were much higher at

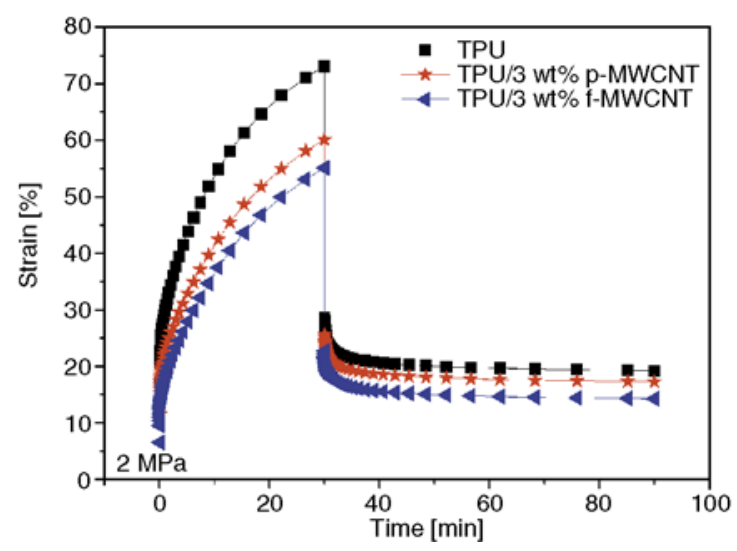

Figure 8. Creep-recovery curves of TPU, TPU/p-MWCNT and TPU/f-MWCNT composites at $2 \mathrm{MPa}$ in the temperature condition of $110^{\circ} \mathrm{C}$.

$110^{\circ} \mathrm{C}$ than those at $35^{\circ} \mathrm{C}$. However, on the contrary with the strong temperature dependence of pure TPU, the roles of nanotubes acting under both temperatures conditions are similar and the enhancement of nanotubes of creep and recovery properties in TPU matrix is not sensitive with temperature change.

\section{Conclusions}

Ozone treated MWCNTs filled TPU composites are prepared by diluting a masterbatch containing $15 \mathrm{wt} \%$ MWCNTs using melt mixing. The findings highlighted in this paper contribute to our understanding on the efficiency of ozonization of TPU/ MWCNT nanocomposites. Some conclusions can be obtained so far:

1 The MWCNTs functionalized by ozone showed better dispersion with the TPU matrix as compared to the unmodified ones.

2 Significant improvements in Young's modulus and tensile strength of the f-MWCNTs/TPU composites were obtained in comparison with that of p-MWCNTs/TPU composites. Ozone functionalization was an effective method to surface-modify the CNTs and improve the related mechanical properties of TPU matrix.

3 The surface modification of MWCNTs obtained by ozone treatment can influence in the creep and recovery property of the nanocomposites in different temperature conditions. The strong interaction between f-MWCNTs and TPU matrix would facilitate the load transfer, resulting in low creep strain and unrecovered strain. 


\section{Acknowledgements}

This project was jointly supported by the National Nature Science Foundation of China (Grant No. 51073044), a key international collaboration project (Grant No. 2011DFR50200) of the Ministry of Science and Technology of China, and a key item of the Knowledge Innovation Project of the Chinese Academy of Science (Grant No. KJCX2-YW-M20).

\section{References}

[1] Nguyen D. A., Lee Y. R., Raghu A. V., Jeong H. M., Shin C. M., Kim B. K.: Morphological and physical properties of a thermoplastic polyurethane reinforced with functionalized graphene sheet. Polymer International, 58, 412-417 (2009).

DOI: $10.1002 /$ pi.2549

[2] Mishra A. K., Mushtaq S., Nando G. B., Chattopadhyay S.: Effect of Cloisite and modified Laponite clays on the rheological behavior of TPU-clay nanocomposites. Rheologica Acta, 49, 865-878 (2010). DOI: $10.1007 / \mathrm{s} 00397-010-0458-5$

[3] Lai S-M., Wang C-K., Shen H-F.: Properties and preparation of thermoplastic polyurethane/silica hybrid using sol-gel process. Journal of Applied Polymer Science, 97, 1316-1325 (2005).

DOI: 10.1002/app.21833

[4] Koerner H., Liu W., Alexander M., Mirau P., Dowty H., Vaia R. A.: Deformation-morphology correlations in electrically conductive carbon nanotube-thermoplastic polyurethane nanocomposites. Polymer, 46, 4405-4420 (2005).

DOI: $10.1016 /$ j.polymer.2005.02.025

[5] Jimenez G. A., Jana S. C.: Oxidized carbon nanofiber/ polymer composites prepared by chaotic mixing. Carbon, 45, 2079-2091 (2007).

DOI: $10.1016 / \mathrm{j}$. carbon.2007.05.015

[6] Dan C. H., Lee M. H., Kim Y. D., Min B. H., Kim J. H.: Effect of clay modifiers on the morphology and physical properties of thermoplastic polyurethane/clay nanocomposites. Polymer, 47, 6718-6730 (2006). DOI: 10.1016/j.polymer.2006.07.052

[7] Ajayan P. M., Iijima S.: Smallest carbon nanotube. Nature, 358, 23 (1991).

DOI: $10.1038 / 358023 \mathrm{a} 0$

[8] Kashiwagi T., Grulke E., Hilding J., Groth K., Harris R., Butler K., Shields J., Kharchenko S., Douglas J.: Thermal and flammability properties of polypropylene/carbon nanotube nanocomposites. Polymer, 45, 4227-4239 (2004).

DOI: $10.1016 /$ j.polymer.2004.03.088

[9] Koval'chuk A. A., Shchegolikhin A. N., Shevchenko V. G., Nedorezova P. M., Klyamkina A. N., Aladyshev A. M.: Synthesis and properties of polypropylene/multiwall carbon nanotube composites. Macromolecules, 41, 3149-3156 (2008).

DOI: $10.1021 / \mathrm{ma} 800297 \mathrm{e}$
[10] Kim M., Mun S. C., Lee C. S., Lee M. H., Son Y., Park O. O.: Electrical and rheological properties of polyamide $6,6 / \gamma$-ray irradiated multi-walled carbon nanotube composites. Carbon, 49, 4024-4030 (2011). DOI: 10.1016/j.carbon.2011.05.044

[11] Yuan J-M., Fan Z-F., Chen X-H., Chen X-H., Wu Z-J., He L-P.: Preparation of polystyrene-multiwalled carbon nanotube composites with individual-dispersed nanotubes and strong interfacial adhesion. Polymer, 50, 3285-3291 (2009). DOI: 10.1016/j.polymer.2009.04.065

[12] Sarno M., Gorrasi G., Sannino D., Sorrentino A., Ciambelli P., Vittoria V.: Polymorphism and thermal behaviour of syndiotactic poly(propylene)/carbon nanotube composites. Macromolecular Rapid Communications, 25, 1963-1967 (2004). DOI: $10.1002 /$ marc. 200400344

[13] Tjong S. C., Liang G. D., Bao S. P.: Electrical behavior of polypropylene/multiwalled carbon nanotube nanocomposites with low percolation threshold. Scripta Materialia, 57, 461-464 (2007). DOI: $10.1016 /$ j.scriptamat.2007.05.035

[14] Li M., Boggs M., Beebe T. P., Huang C.: Oxidation of single-walled carbon nanotubes in dilute aqueous solutions by ozone as affected by ultrasound. Carbon, 46, 466-475 (2008).

DOI: $10.1016 /$ j.carbon.2007.12.012

[15] Banerjee S., Wong S. S.: Rational sidewall functionalization and purification of single-walled carbon nanotubes by solution-phase ozonolysis. Journal of Physical Chemistry B, 106, 12144-12151 (2002). DOI: $10.1021 / j p 026304 \mathrm{k}$

[16] Cai L., Bahr J. L., Yao Y., Tour J. M.: Ozonation of single-walled carbon nanotubes and their assemblies on rigid self-assembled monolayers. Chemistry of Materials, 14, 4235-4241 (2002).

DOI: $10.1021 / \mathrm{cm} 0202730$

[17] Sham M-L., Kim J-K.: Surface functionalities of multiwall carbon nanotubes after UV/ozone and TETA treatments. Carbon, 44, 768-777 (2006).

DOI: $10.1016 /$ j.carbon.2005.09.013

[18] Byl O., Liu J., Yates Jr. J. T.: Etching of carbon nanotubes by ozone - A surface area study. Langmuir, 21, 4200-4204 (2005). DOI: $10.1021 / 1 \mathrm{a} 040132 \mathrm{w}$

[19] Mawhinney D. B., Naumenko V., Kuznetsova A., Yates Jr. J. T., Liu J., Smalley R.: Infrared spectral evidence for the etching of carbon nanotubes: Ozone oxidation at $298 \mathrm{~K}$. Journal of the American Chemical Society, 122, 2383-2384 (2000). DOI: $10.1021 /$ ja994094s

[20] Simmons J. M., Nichols B. M., Baker S. E., Marcus M. S., Castellini O. M., Lee C-S., Hamers R. J., Eriksson M. A.: Effect of ozone oxidation on single-walled carbon nanotubes. Journal of Physical Chemistry B, 110, 7113-7118 (2006).

DOI: $10.1021 / j p 0548422$ 
[21] Peng K., Liu L-Q., Li H., Meyer H., Zhang Z.: Room temperature functionalization of carbon nanotubes using an ozone/water vapor mixture. Carbon, 49, 70-76 (2011).

DOI: $10.1016 /$ j.carbon.2010.08.043

[22] Tang L-C., Zhang H., Han J-H., Wu X-P., Zhang Z.: Fracture mechanisms of epoxy filled with ozone functionalized multi-wall carbon nanotubes. Composites Science and Technology, 72, 7-13 (2011). DOI: 10.1016/j.compscitech.2011.07.016

[23] Zhang Z., Peng K., Chen Y.: Mechanical performance of ozone functionalized MWCNTs/PC nanocomposites. Express Polymer Letters, 5, 516-525 (2011). DOI: $10.3144 /$ expresspolymlett.2011.50

[24] Ward I. M.: Mechanical properties of solid polymers. Wiley, Weinheim (1983).

[25] Kao C. C., Young R. J.: A Raman spectroscopic investigation of heating effects and the deformation behaviour of epoxy/SWNT composites. Composites Science and Technology, 64, 2291-2295 (2004).

DOI: 10.1016/j.compscitech.2004.01.019
[26] Cooper C. A., Young R. J., Halsall M.: Investigation into the deformation of carbon nanotubes and their composites through the use of Raman spectroscopy. Composites Part A: Applied Science and Manufacturing, 32, 401-411 (2001).

DOI: 10.1016/S1359-835X(00)00107-X

[27] Ma H., Zeng J., Realff M. L., Kumar S., Schiraldi D. A.: Processing, structure, and properties of fibers from polyester/carbon nanofiber composites. Composites Science and Technology, 63, 1617-1628 (2003). DOI: $10.1016 / \mathrm{S} 0266-3538(03) 00071-X$

[28] Jia Y., Peng K., Gong X-L., Zhang Z.: Creep and recovery of polypropylene/carbon nanotube composites. International Journal of Plasticity, 27, 1239-1251 (2011).

DOI: $10.1016 /$ j.ijplas.2011.02.004 